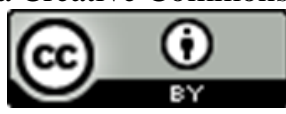

\title{
SEGREGAÇÃO RACIAL E DESIGUALDADES URBANAS NAS CIDADES BRASILEIRAS: ELEMENTOS PARA UMA OBSERVAÇÃO DA NECROPOLÍTICA
}

\section{Reinaldo José de Oliveira ${ }^{1}$}

Resumo: O presente texto aborda a segregação racial e as desigualdades urbanas em dez urbes com maior participação da população negra, o rendimento nominal médio entre negros e brancos e analisa as referências teórico metodológicas da produção nacional sobre cidade, urbanismo e relações étnico raciais. A observação da segregação retrata elementos para compreender o debate em torno da necropolítica e da política antinegro. Neste século XXI, o avanço em torno do desenvolvimento da cidadania será o enfrentamento da segregação racial com políticas públicas com foco nas relações étnico raciais.

Palavras-Chave: cidade, desigualdades, necropolítica, segregação racial e racismo.

\section{RACIAL SEGREGATION AND URBAN INEQUALITIES IN BRAZILIAN CITIES: ELEMENTS FOR AN OBSERVATION OF THE NECROPOLITICS}

Abstract: The present text addresses racial segregation and urban inequalities in ten cities with a greater participation of the black population, the average nominal income between blacks and whites and analyzes the theoretical methodological references of national production on city, urbanism and ethnic racial relations. The observation of segregation portrays elements to understand the debate around necropolitics and antiblack politics. In this 21st century, the advancement around the development of citizenship will be the confrontation of racial segregation with public policies with a focus on ethnic racial relations.

Keywords: city, inequalities, necropolitics, racial segregation and racism.

\section{SEGREGACIÓN RACIAL Y DESIGUALDADES URBANAS EN CIUDADES BRASILEÑAS: ELEMENTOS PARA LA OBSERVACIÓN DE LAS NECROPOLÍTICAS}

\footnotetext{
${ }^{1}$ Sociólogo, Doutor em Ciências Sociais pela Pontifícia Universidade Católica de São Paulo. Professor do Centro de Formação de Professores, UFRB e IFBA Campus Catu. ORCID: https://orcid.org/00000003-3770-7862 E-mail: reinaldo.jose@uol.com.br
} 
Resumen: El presente texto aborda la segregación racial y las desigualdades urbanas en diez ciudades con una mayor participación de la población negra, el ingreso nominal promedio entre negros y blancos y analiza las referencias metodológicas teóricas de la producción nacional sobre la ciudad, el urbanismo y las relaciones raciales étnicas. La observación de la segregación retrata elementos para comprender el debate sobre la necropolítica y la política anti-negra. En este siglo XXI, el avance en torno al desarrollo de la ciudadanía será la confrontación de la segregación racial con políticas públicas centradas en las relaciones raciales étnicas.

Palabras clave: ciudad, desigualdades, necropolítica, segregación racial y racismo.

\section{SÉGRÉGATION RACIALE ET INÉGALITÉS URBAINES DANS LES VILLES BRÉSILIENNES: ÉLÉMENTS POUR UNE OBSERVATION DE LA NÉCROPOLITIQUE}

Résumé: Ce texte discute de la ségrégation raciale et des inégalités urbaines dans dix villes avec une plus grande participation de la population noire, le revenu nominal moyen entre noirs et blancs et analyse les références méthodologiques théoriques de la production nationale sur la ville, l'urbanisme et les relations raciales ethniques. L'observation de la ségrégation dépeint des éléments pour comprendre le débat autour des politiques nécropolitiques et anti-noires. Au XXIe siècle, l'avancement du développement de la citoyenneté sera la confrontation de la ségrégation raciale aux politiques publiques en mettant l'accent sur les relations raciales ethniques.

Mots clés: citoyenneté, inégalités, nécropolitiques, ségrégation raciale et racisme.

\section{INTRODUÇÃO}

As cidades brasileiras no século XX, principalmente nas últimas três décadas, alcançaram um quadro de urbanização e desenvolvimento de grande dinamismo, sem estar integralmente prontas para responder às principais demandas da população quanto a cidadania, em especial, da população negra.

Conforme Raquel Rolnik (1997), a ideia de cidade legal compreende um cenário de urbanização, produção do espaço e reprodução de fixos e fluxos do ambiente construído $^{2}$, regida por uma legislação determinada pelo poder público.

\footnotetext{
${ }^{2}$ Ambiente Construído: refere-se ao conjunto de elementos fixos e fluxos, como hospitais, unidades de saúde; sistema público e privado de transportes de ônibus, metrô, trem, taxi, uber; centros e equipamentos de cultura, são as bibliotecas, pontos de cultura, parques, salas de cinema e teatro, organizações e associações de culturas populares; centros de abastecimento de alimentos como mercados, feiras; centros de negócios econômicos, sociais e culturais, como os shopping centers, lojas dos mais diferentes segmentos comerciais, enfim, o ambiente construído é essencial na produção e reprodução social do espaços das urbes contemporâneas.
} 
Nos municípios do país, principalmente as grandes urbes, a legislação tem respondido a um conjunto de mecanismos de controle e vigilância, que determina os seguintes cenários: de uma lado, por intermédio do quadro socioeconômico e político, oficializa um pedaço da cidade que funcionará conforme as regras estabelecidas pelo poder e, por outro lado, na cidade real, a legislação coloca a maioria da população, principalmente os grupos de menor poder aquisitivo "fora da lei", ou seja, a lei estabelece àqueles que podem viver na cidade real.

Na cidade "fora da lei", vigora a produção e reprodução do espaço social de subrepresentação socioeconômica, por exemplo, da habitação em loteamentos irregulares, construída nas periferias cada vez mais nos limites ou em áreas centrais, porém, distante da hierarquia social, como as favelas, cortiços, porões, palafitas e a multidão sem o encontro do diálogo, da troca e da vida social. As cidades de grande porte que apresentam as faces do capitalismo global, nacional e sul-americano, como São Paulo, Rio de Janeiro, Salvador, Belo Horizonte, predomina as faces da cidade fora da lei.

Nas urbes do capitalismo global, nacional, regional e local, a população negra vive e resiste às formas de limpeza, higienização e exclusão do direito à cidade. Nesse momento, século XXI, é importante constituir um balanço da segregação que condiciona à população negra os últimos lugares e posições na sociedade brasileira.

A negação das relações étnicas e raciais nos espaços sociais e na cidade como um todo, reitera a ideia do mito da igualdade racial nas cidades brasileiras, na teoria isso vem acontecendo quando o tema é invisibilizado e apagado dos principais centros de discusão. Na prática, a cartografia da segregação tem crescido cada vez mais com a presença negra.

Procurarei problematizar a segregação racial e refletir as seguintes questões: como as categorias socioeconômica, étnico e raciais, principalmente da população negra repercutem na segregação?

Do final da década de 1990 até a nossa contemporaneidade, importantes referências sobre a cidade e o urbano com foco na população negra foram se estruturando, se fortalecendo no arcabouço teórico metodológico, dentre eles, destacamos, Edward Telles (1994; 2003), Reinaldo José de Oliveira (1998; 2002; 2008), Andrelino Campos (2007), Antonia dos Santos Garcia (2009), André Augusto Brandão (2004), Lourdes Carril, (2006) e Maria Nilza da Silva (2006). 
Nas páginas abaixo, apresento interpretações sobre o conceito teórico metodológico da segregação racial no Brasil, a partir do olhar das cidades: do universo das cem maiores urbes com população negra, destaco dez cidades e a capital federal; das dez urbes selecionadas, evidencio os dados absolutos da população entre brancos e negros e renda/rendimento, enquanto elementos que retratam o quadro da necropolítica.

A abordagem sobre a segregação foi recebendo novas intepretações, conforme as pesquisas que realizei no doutorado até o presente momento. Em 2013, organizei a obra "A Cidade e o Negro no Brasil: cidadania e território", nessa produção avanços substanciais foram delimitados sobre o tema. Posteriormente, em 2016, a produção do livro "Territorialidade Negra e Segregação Racial na cidade de São Paulo: A luta por cidadania no século XX", trago interpretações comparativas dos censos do IBGE, de 2000 e 2010 sobre as interfaces entre as desigualdades urbanas e raciais. Dentre as problematizações, faço a seguinte pergunta: De 2000 a 2010, a segregação racial avançou na cidade de São Paulo? Avalio que nesse momento, século XXI, o enfrentamento da segregação racial e das desigualdades urbanas, enquanto elementos que refletem a necropolítica, deve seguir uma orientação de políticas públicas com foco nas desigualdades étnico raciais.

\section{SEGREGAÇÃO URBANA E RACIAL NO BRASIL}

As sociedades capitalistas modernas e contemporâneas trazem um marco no contexto da cidade e do urbano, que afeta a todos os que vivem e (re)produzem o espaço social: a questão da segregação.

A literatura sobre o tema compreende abordagens que focalizam, em geral, a luta entre as classes sociais em torno do espaço e do ambiente construído (LOJKINE, 1997; CASTELLS, 1983; VILLAÇA, 2001; VÉRAS, 2000; RIBEIRO, 1997), com exceção das sociedades norte-americano e sul-africana, onde o recorte de separação foi estruturado pela segregação racial. Nestas sociedades, o próprio Estado legalizou a prática da segregação entre brancos e negros, privilegiando os primeiros em todos os lugares da sociedade, como o acesso aos serviços públicos e privados de consumo coletivos; escolas, universidades, habitações, centros de cultura e lazer, mercado de trabalho, transporte, dentre outras. 
Nas Américas, principalmente a de origem latina, as etnias e relações raciais se inscreveram muito antes da colonização espanhola e portuguesa. As etnias e suas formas de organização social, cultural e espacial, antecedem a arquitetura e a produção da cidade ibérica.

Conforme Anibal Quijano (2005), o espaço social, os territórios e as territorialidades da América Latina foram fundados com o derramamento de sangue dos povos e culturas indígenas e africanas. As dezenas e centenas de culturas e etnias, gradativamente, foram transformadas em indígenas e negros nas Américas, sobretudo no Brasil.

No chão do território nacional, estão permeados o sangue e a cultura da diversidade que edificou o país: no passado, prevalecia a diversidade de povos de diferentes culturas, na atualidade, temos os nativos das culturas ticuna, guarani, caiagangue, macuxi, terena, guajajara, xavante, ianomâmi, pataxó e pataxó; dentre os povos e etnias escravizadas, os africanos eram descendentes de sudaneses, iorubas, jejês, ashantis, bantus.

Uma marca terrível da colonização no novo mundo foi a gradual eliminação da diversidade, das culturas nativas e africanas. A barbárie teve início desde a ideia de "fundação" do Brasil, toda a riqueza de conhecimentos, línguas, gestos, organização social e espacial, todos os povos foram resumidos em indígenas e negros.

No Brasil, o legado e as inscrições de indígenas e africanos estão inscritos no chão das cidades. O quadro literário sobre a cidade e o urbano em diálogo com as relações étnicas raciais é uma construção de ideias e reflexões que marcaram a colonização e a contemporaneidade, principalmente da hierarquia do poder, referentes à classe social, etnia raça e gênero (VARGAS, 2005; CARRIL, 2006; SILVA, 2006; CAMPOS, 2007; OLIVEIRA, 2013;2016; GARCIA, 2010; SOUZA, 2015).

A segregação da pobreza ou a segregação da riqueza é referência base da literatura nacional, não é eficaz em problematizar o quadro da população negra nas cidades brasileiras. É preciso problematizar que a questão das desigualdades e da marginalização da população negra na história do século XX e no atual momento, não se resume ao cenário da pobreza.

Nas sociedades norte-americano e sul-africana, a segregação racial beneficiou a população de origem branca e anglo-saxã. No Brasil, a segregação mantém vantagens 
materiais e simbólicas aos segmentos brancos de todas as classes sociais. Aos negros, sobretudo aos subproletários, são reservados os últimos lugares das cidades, em condições de marginalidade e a ausência de equipamentos de uso coletivo que compõem o ambiente construído nas urbes do país. Parte deste cenário, pode ser melhor explicado, conforme as informações das tabelas 1 e 2 , as desigualdades de rendimento entre brancos e negros, como elementos do quadro da necropolítica.

Nos últimos 132 anos, a literatura acadêmica sobre a cidade e o urbano não observa as categorias etnia raça como centrais (CORREA, 1995; RIBEIRO, 1997; VILLAÇA, 2001; MARQUES, 2005). Segundo Vargas (2005), esses trabalhos observam aspectos da segregação espacial sem problematizar as categorias etnia raça.

Autores de destaque da literatura nacional sobre a cidade e o urbano (MARICATO, 1996; RIBEIRO, 1997; LAGO, 2000; VILLAÇA, 2001; MARQUES, 2005) observam a segregação no Brasil, em geral, a separação socioeconômica e espacial: a) a versão centro-periferia, que se popularizou em todas as cidades e metrópoles do país; b) a proximidade física, a partir da distância socioeconômica que separa as classes sociais e seus respectivos lugares na cidade.

Para melhor compreender a segregação racial no país, primeiramente observo as inscrições da população negra no chão das cidades brasileiras. Em São Paulo e Rio de Janeiro, desde as últimas décadas do século XIX até o momento atual, o Estado e os agentes do mercado capitalista da terra e da habitação trataram de limpar, inicialmente, o centro e manter sob controle a população negra nas periferias, morros e nas áreas de pouco interesse do capital imobiliário (CHALHOUB, 1990; SILVA, 2006; CARRIL, 2006; OLIVEIRA, 2008).

O Estado e os agentes do capital imobiliário da terra e da habitação são os atores responsáveis pela desterritorialização de antigos núcleos negros nas principais urbes do país. A territorialidade-desterritorialidade-reterritorialidade é o movimento de forças materiais e simbólicas em constante metamorfose nos espaços sociais e nas cidades, influenciada por fatores sociais, culturais, políticos e econômicos, por exemplo, a identidade social, religião, cultura, gênero, faixa etária, dentre outros. Nas principais urbes do país, os territórios e territorialidades negras representam o seguinte cenário: as organizações sociais, culturais, econômicas e políticas que trabalham a produção de enfrentamentos ao racismo; buscam a valorização das identidades negras, por 
intermédio das artes e culturas africana e afro-brasileira; protagonizam a formação identitária de jovens, adolescentes e mulheres negras; os grupos de jovens e adolescentes que curtem e fazem a cultural hip hop; os cursinhos pré-vestibular voltados para a população negra e pobre; as religiões de matriz africana e afrobrasileira, como o candomblé e a umbanda; as comunidades de remanescentes de quilombos, enfim, as territorialidades que se inscrevem no chão das cidades (dos espaços urbano e rural) na insistente luta em torno da cidadania.

Um retrato do movimento territorialidade-desterritorialidade-reterritoriliadade é o cenário da história dos quilombos rurais, semiurbanos e urbanos, em sucessivas etapas proporcionadas pelo desenvolvimento e o mundo urbano industrial, foram perdendo espaço para dar lugar aos planos de urbanização, que tinham como objetivos tornar as cidades modernas, belas e desenvolvidas. Os benefícios trazidos com o progresso e a modernidade não incluíram a população egressa do trabalho escravo, enfim, ela não foi incluída à cidade e aos benefícios diretos e indiretos do mundo urbano industrial (FERNANDES, 1965; PINTO, 1998).

Pensando o delineamento da segregação racial, problematizo a seguir, dez argumentos para retratar a influência do mito da democracia racial, as desigualdades urbanas e o legado do escravismo no chão das cidades brasileiras, sobretudo no urbano.

O primeiro argumento está estruturado nas ideias de Emilia Viotti da Costa (1995), tendo como referência a lei de terras, de 1850: a legislação determinava que o acesso à terra passava pelo quadro socioeconômico, ou seja, a terra recebe a condição de mercadoria, gradativamente, com a aproximação da abolição, o governo imperial queria impedir que os escravizados se tornassem proprietários de terras nos espaços das cidades. A lei de terra configurou a segregação da população negra nos espaços urbano e rural. Portanto, a política antinegro privou negros e negros do direito à terra.

O segundo argumento apoia-se no contexto das três primeiras décadas do século XX, com a inauguração da Universidade de São Paulo. Dentre os professores estrangeiros, destaca-se o antropólogo Claude Lévi-Strauss (1996). Em Tristes Trópicos, o autor nos apresenta faces da etnografia urbana, da qual observa a estrutura da segregação nas urbes de São Paulo de Rio de Janeiro.

Pastos de vacas estendem-se ao pé de imóveis em concreto, um bairro surge como uma miragem, avenidas ladeadas de luxuosas residências são 
interrompidas de um lado e outro por ribanceiras; ali, uma torrente barrenta circula entre as bananeiras, servindo ao mesmo tempo de nascente e de esgoto para casebres de taipa sobre estrutura de bambu, onde se encontra a mesma população negra que, no Rio, se instala no alto dos morros (...) Certos locais privilegiados da cidade conseguem acumular todos os aspectos. Assim, à saída de duas ruas divergentes que seguem em direção do mar, desembocamos na beira do barranco do Rio Anhangabaú, cruzado por uma ponte que é uma das principais artérias da cidade (...)

(...) Talvez, o urbanismo tenha agora resolvido o problema, mas em 1935, no Rio, o lugar ocupado por cada um na hierarquia social media-se pelo altímetro: tanto por mais baixo quanto mais alto fosse o domicílio. Os miseráveis viviam empoleirados nos morros, nas favelas onde populações de negros, vestidos de trapos bem limpinhos inventavam ao violão melodias alertas que, na época do Carnaval, desceriam das alturas e invadiram a cidade junto com eles (LÉVISTRAUSS, 1996, p.83 e 95).

Desde as primeiras décadas do século $\mathrm{XX}$, o retrato etnográfico da população negra nas cidades de São Paulo e Rio de Janeiro não passou por transformações estruturais; negros e negras continuam nos bairros e territórios da pobreza, distantes das melhores áreas, ricas e desenvolvidas ou próximas, mas distantes da hierarquia socioeconômica.

A literatura nacional concentra sua abordagem na tradicional leitura sobre o espaço social, que é a versão histórica sobre a separação socioeconômica. Esta leitura incorporou a pobreza do contexto urbano e da cidade; diante deste jogo de poder socioeconômico e político, a população negra está circunscrita à segregação da pobreza.

É majoritária a referência da literatura nacional em torno da produção da EFSUM- Escola Francesa de Sociologia Urbana de orientação Marxista. A literatura nacional orientou-se em estudos sobre a regularização fundiária, a ação do Estado, o saneamento, a questão da habitação e a distribuição diferenciada das residências no espaço urbano.

Dos anos 1970 até o final de 1990, prevaleceu a produção brasileira (dissertações e teses) nessa área de ensino e pesquisa, aplicando e desenvolvendo o conceitual teórico metodológico da EFSUM (PACHECO e LEME, 1994). A EFSUM foi e continua sendo referência para a produção nacional; através deste recorte, a literatura da academia brasileira compôs as primeiras observações sobre a segregação urbana, a luta dos movimentos sociais urbanos em torno do ambiente construído, a espoliação urbana e o crescimento desordenado da cidade, principalmente das habitações fora da lei (favelas, loteamentos irregulares, autoconstruções e palafitas). No 
entanto, a produção relacionando espaço urbano e etnia raça teve origem no final da década de 1980.

Os estudos sociológicos em relações e raciais, sobretudo as obras patrocinadas pela UNESCO, Revista Anhembi e Convênio Estado da Bahia - Columbia University tiveram a direção intelectual de pesquisadores nacionais e estrangeiros: Gilberto Freyre, Charles Wagley, Donald Pierson, Roger Bastide, na primeira geração; Florestan Fernandes, Costa Pinto e Thales de Azevedo, Oracy Nogueira, René Ribeiro, Guerreiro Ramos, Pierre van den Berghe e Marvin Harris, na segunda geração; Fernando Henrique Cardoso e Octávio Ianni, na terceira gerações (GUIMARÃES, 1999).

Os estudos promovidos por estes pesquisadores, mediante as linhas de pensamento, chegaram a três interpretações. Parte dos estudos realizados na Bahia, Recife e Norte do país, chegaram a conclusões de que o preconceito racial era fraco, senão inexistente no Brasil. Nos estudos realizados em São Paulo, Rio de Janeiro e sul do país, a documentação analisada interpretou que o preconceito no país é intenso, porém, é negado e mascarado nos espaços públicos e privados.

Segundo outra versão, haveria uma discordância ideológica e política entre a escola paulista e a escola baiana acerca do contexto sociocultural da sociedade brasileira. Os estudos da produção paulista comprovaram o crescimento do racismo no país, enquanto a referência baiana teria defendido o ideal da democracia racial (GUIMARÃES, 1999).

A terceira versão tem por objetivo destacar as linhas de pensamento, as diferenças entre as faces do moderno e o tradicional, em termos de preconceito e de relações raciais que se estruturaram em diferentes escolas, do ponto de vista metodológico e interpretativo, fundamentais para a análise histórica e contemporânea sobre as desigualdades no país.

Conforme comentários acima, a literatura que se apoia na produção da EFSUM define a luta de classes e os desdobramentos da produção e reprodução do espaço social como os objetos centrais para compreender e interpretar a segregação brasileira. Já a produção nacional sobre relações raciais priorizou a inserção da população negra na sociedade de classes, o quadro socioeconômico do desenvolvimento nacional e as organizações do universo cultural afro-brasileiro (ROLNIK, 1989; OLIVEIRA, 2008; 2016). 
O terceiro argumento trata da leitura sociológica da cidade de São Paulo nas três primeiras décadas do século XX. Florestan Fernandes e Roger Bastide (1971) publicaram o primeiro estudo sobre relações raciais em São Paulo, referente às primeiras décadas pós-abolição. Constataram que a ideia de paraíso racial não era real, não existe igualdade na realidade brasileira.

Nos idos de 1930, em bairros como Bixiga, Barra Funda, Liberdade e nas áreas centrais, negros e brancos compartilhavam o mesmo espaço geográfico. Compartilhavam da mesma geografia social, mas prevalecia a hierarquia e a sobrerrepresentação negra nos subterrâneos das cidades: nos cortiços e porões (OLIVEIRA, 2002; 2008).

O quarto argumento, apoiado na obra de Luiz da Costa Pinto (1998), analisa a segregação da população negra na cidade do Rio de Janeiro, nos idos de 1940. A leitura da segregação da ex-capital federal é observada por intermédio de três categorias: a posição social, a situação ecológica e a condição étnica. Cada pedaço da cidade é ocupado conforme a condição do ambiente construído: quanto maior a urbanização, mais a participação de brancos e, no sentido inverso, quanto menor a urbanização, maior a participação de negros.

$\mathrm{O}$ quinto argumento tem como fundamento as ideias de Abdias do Nascimento, um protagonista social que esteve em várias frentes: ex-Secretário de Estado do Rio de Janeiro, ex-Senador da República, ex-deputado, escritor, artista plástico, docente em universidades norte-americanas e militante social negro. Abdias do Nascimento (1978; 2006) assinala em dois momentos a segregação na cidade do Rio de Janeiro, tendo como protagonista o morro, as favelas e o subúrbio. Em 1950, organiza e lidera juntamente com os movimentos sociais negros proposições de intervenção referentes ao quadro da população negra na sociedade nacional, com o objetivo de descaracterizar e combater o mito da igualdade racial, como, por exemplo, ao descrever e tornar público o estado de pobreza negra na ex-capital federal.

É importante destacar que a imprensa negra e os movimentos sociais negros desde as primeiras décadas do século XX já traziam a problematização das políticas públicas para a superação do racismo e da necropolítica. A Imprensa Negra e o Teatro Experimental do Negro, em suas ações problematizavam e vinculavam as questões mais 
centrais ao universo da população negra, haja vista os trabalhos desenvolvidos nas áreas de educação, formação profissional para acesso e mobilidade no mercado de trabalho.

Nos idos de 2006, Abdias do Nascimento tece considerações sobre a segregação no Rio de Janeiro, reiterando a expansão em direção à região metropolitana, como Baixada Fluminense, que vive os estereótipos da marginalização social, das práticas abusivas da violência e, de forma sistemática, o poder do tráfico de drogas (NASCIMENTO, 2006).

No percurso histórico e político de Abdias do Nascimento, um tema central é a luta por igualdade e a busca incessante da verdadeira democracia brasileira. O exercício de atividades políticas e sociais no âmbito institucional e na sociedade foram e são importantes para o desenvolvimento de políticas de promoção da igualdade racial, que na etapa atual se concretizaram com a aprovação do Estatuto da Igualdade Racial, a política de ações afirmativa e a lei $10.639 / 2003^{3}$.

Hoje, o quadro das desigualdades entre brancos e negros não sofreu grandes mudanças estruturais. A distribuição entre brancos e negros nas urbes fluminense e paulistana contextualiza-se num contexto semelhantes ao passado; antes, eles estavam nos cortiços e porões, hoje, eles se encontram nos espaços reservados às periferias, morros, favelas, loteamentos distantes e em posição marginalizada no quadro urbano e da cidade (FERNANDES, 1989; OLIVEIRA, 2008; 2016).

O sexto argumento tem como referência Gonzales e Hasenbalg (1982), que descrevem os lugares habitados por brancos e negros nas cidades brasileiras. Conforme os autores, da cidade escravista à cidade contemporânea, brancos e negros ocupam diferentes posições socioeconômicas e territoriais no Brasil:

O lugar natural do grupo branco dominante são moradias amplas, espaçosas, situadas nos mais belos recantos, da cidade ou do campo e devidamente protegidas por diferentes tipos de policiamento: desde os antigos feitores, capitães do mato, capangas, etc, até a polícia formalmente constituída. Desde a

\footnotetext{
${ }^{3}$ O Estatuto da Igualdade Racial aprovado em 2010, no Senado Federal e sancionado pelo então Presidente da República, Luiz Inácio Lula da Silva, não incorporou os principais temas de interesse da população negra, em especial, a política de cotas nas universidades públicas e políticas de saúde para a população negra. Em 2020, serão completados 10 anos do Estatuto da Igualdade Racial, os avanços são significativos, mas para o enfrentamento da segregação racial será preciso que as políticas públicas e sociais elaboradas no referido documento, gradualmente, saiam do papel para a refletir na realidade social de milhões de brasileiros no território nacional.
} 
casa grande e o sobrado, aos belos edifícios tem sido sempre o mesmo. Já o lugar natural do negro é o oposto, evidentemente: das senzalas às favelas, cortiços, porões, invasões, alagados e conjuntos habitacionais (...) (GONZALES E HASENBALG, 1982).

Espacialmente e temporalmente, por mais de 130 anos os lugares e posições sociais da população negra nas cidades brasileiras permaneceram os mesmos.

O sétimo argumento apoia-se em Hasenbalg (2005), o qual observa que a pósabolição e a inserção da população negra na sociedade de classes não se concretizou em grandes benefícios, em condições socioeconômicas semelhantes ao quadro social da população branca.

A ausência de segregação legal no Brasil acentua o quadro das relações raciais e, em especial, a crença no mito da igualdade racial. A população negra é majoritária no subproletariado e para ela decaem dificuldades de mobilidade para ascender, está vinculada à origem social, ao lugar espacial que lhe é imposto e à ordem de classes, que delimita os lugares na sociedade brasileira, como o mercado de trabalho e a educação, espaços que poderão, no futuro, viabilizar a mobilidade e o direito à cidade.

Como argumenta Hasenbalg (2005), a sociedade brasileira mantém a estrutura de privilégio branco e a subordinação negra, evita a constituição da raça como princípio de identidade coletiva e ação política. O mito da igualdade racial manifesta-se na ausência de conflitos raciais abertos, na segregação da pobreza e na desmobilização política dos negros, fazendo com que os componentes racistas do sistema permaneçam incontestados, sem necessidade de recorrer a um alto grau de coerção.

Desde as últimas décadas do século $\mathrm{XX}$, o movimento social negro vem fortalecendo a luta contra o mito da democracia racial sobretudo com a produção e conquista de políticas de promoção dos direitos sociais e raciais. No entanto, os conflitos não se materializam em mudanças estruturais na hierarquia social e na estrutura que mantêm a população negra no lugar de lupemproletariado e da necropolítica.

O oitavo argumento é assegurado por Buarque (1993), que declara que o país vive o apartheid social, onde os direitos básicos de cidadania não são respeitados em relação aos mais pobres, sobretudo aos negros. Os negros são excluídos não apenas pela pobreza, mas também pela cor, sofrendo duplo apartheid, o racial e o econômico, que 
são de difícil superação com a ausência de políticas que combinem as desigualdades sociais e as desigualdades raciais.

A leitura contemporânea sobre a necropolítica perfaz o nono argumento. Achille Mbembe (2016) problematiza ideias e reflexões sobre as sociedades que inscreveram na história os cenários de colonização, escravismo, totalitarismo, ditaduras, guerras e a ausência de Estado de Direitos. Todo esse contexto da necropolítica retrata quem pode viver e quem pode morrer nas sociedades do capitalismo global.

Segundo Mbembe (2016), no passado e nos dias de hoje, parte do cenário de violência, estupros e genocídios dos corpos (físico e mental), está inscrito no chão dos territórios, territorialidades e das urbes dos Estados do século XXI.

Nas cidades brasileiras, o derramamento de sangue foi regra nos 380 anos da sociedade escravocrata e nos últimos 132 anos da pós-abolição. A força de trabalho de homens e mulheres negras não obteve sucesso no processo histórico e contemporâneo da civilização brasileira para estruturar a igualdade étnico racial.

Na hierarquia socioeconômica do país, a população negra vive a necropolítica em diferentes quadros sociais: o acesso aos serviços e equipamentos de saúde, desde o nascimento, desenvolvimento e morte, a população não alcança as condições semelhantes aos seus pares brancos; no percurso histórico da educação nacional, os segmentos sociais brancos acumularam os principais postos no mercado de trabalho, em serviços públicos e privados; e o lugar de morar, em geral, para a população negra e pobre, resta-lhes o lugar da vulnerabilidade e da segregação.

A necropolítica da realidade brasileira, define quem deve viver e quem deve morrer. A partir das informações do Mapa da Violência no Brasil, por exemplo, de 100 homicídios nos últimos 12 meses, 70 mortes estão relacionadas à população pobre, negra, jovem e moradora das periferias, ou seja, a necropolítica da realidade nacional é negra.

A décima interpretação está centrada nas ideias da necropolítica e da política antinegro, de Achilles Mbembe (2016) e João Vargas (2016). Na realidade nacional, nos últimos 132 anos, as políticas públicas de recorte étnico racial, em geral, não foram inscritas no cotidiano para fins de combater a segregação racial e as desigualdades. $\mathrm{O}$ quadro histórico e atual da população negra nas urbes do país são elementos que retratam a política antinegro. É o que o presente texto irá contextualizar, que a 
segregação racial e as desiguadaldes são elementos da política antinegro e da necropolítica, haja vista as cartrografias da pobreza negra e do genocídio.

As informações socioeconômicas do Censo Demográfico do IBGE, 2000 e 2010, nos proporcionou compor um quadro da segregação racial na sociedade brasileira que é estrutural. Esta é uma leitura que corresponde ao décimo argumento.

Nas próximas páginas, focalizo a leitura da segregação racial nas cidades brasileiras. Das 5.565 urbes que formam o território nacional, selecionei cem urbes, posteriormente, destaquei dez municípios, a partir do recorte das categorias de identificação branca e negra e rendimento.

Em todas as cidades, no quadro das cem urbes e nas dez aqui destacadas, o rendimento nominal médio da população branca é superior ao da população negra. A sobrerrepresentação negra nos rendimentos inferiores aos ganhos da população branca, interpreto que é um quadro que representam elementos da necropolítia e da política antinegro.

Nos principais territórios do capitalismo nacional, sul-americano e global em solo brasileiro, prevalece a sobrerrepresentação negra nos rendimentos mais baixos das principais urbes do país. A população branca está em vantagens materiais (renda/rendimento) em 97,2\% das cidades brasileiras, ou seja, em 5416 urbes do universo das 5565 cidades.

A sobrerrepresentação negra nos menores rendimentos está relacionada ao legado da sociedade escravocrata e os últimos 132 anos da pós-abolição. Este é o quadro da segregação racial, a base da hierarquia socioeconômicas das cidades brasileiras tendo o pleno controle dos corpos da população negra.

A partir dos argumentos acima, interpreto que a segregação é racial, embora, conforme apontei inicialmente, o campo das ciências que observam a cidade e o urbano insiste na assertiva, apenas das desigualdades sociais.

As desigualdades entre brancos e negros diante do contexto da cidade e do urbano ultrapassam a tradicional definição socioeconômica. A concepção de autossegregação ou segregação da pobreza não é suficiente para interpretar a cartografia negra nas cidades brasileiras (OLIVEIRA, 2002; 2008; 2013, 2016). Mesmo nas áreas pobres, negros e negras estão sobrerrepresentados no quadro socioeconômico das desigualdades. 
Portanto, a investigação sobre raça e espaço urbano, em especial, a segregação da população negra, deve ser crítica em razão do silêncio do mito da igualdade racial presente em nossa sociedade; nas universidades, em diversas esferas do Estado (município, estado e união), no mercado de trabalho e nas áreas de melhor remuneração.

Nos últimos 132 anos, a segregação racial vem acompanhada de intensa desigualdades urbanas e raciais nas cidades brasileiras, principalmente nas urbes que são centrais na economia local, regional, nacional e global.

\section{O QUADRO DA SEGREGAÇÃO A PARTIR DA LEITURA DAS DESIGUALDADES URBANAS E RACIAIS}

A distribuição da população negra nas cidades brasileiras está relacionada às questões do passado e do momento atual. Do passado, dos 388 anos de trabalho escravizado nos territórios do país, frente às economias do pau-brasil, cana-de açúcar, açúcar, ouro, minérios, café e inúmeros gêneros alimentícios.

A primeira capital do país, Salvador, se manteve como sede da colonização entre 1549 e 1763. Em solo soteropolitano, durante os 380 anos de escravismo, desembarcaram milhões de africanos que iriam abastecer o comércio e constituir a força de trabalho das principais cidades no escravismo brasileiro.

Salvador, no passado e no momento atual, é a única dentre as capitais do país com o maior percentual de população negra (79,23\%). A ocupação do Estado da Bahia pelas diferentes etnias, gradativamente, foi perfazendo as urbes e regiões de Salvador, Recôncavo da Bahia, Feira de Santana, Sertão, Sudoeste e interior como um todo, são as cidades negras que se destacam nos espaços urbano e rural do estado baiano.

Depois de 1763, a cidade do Rio de Janeiro assume o posto de capital federal, em razão da economia colonial e o escoamento das mercadorias para os portos de Rio de Janeiro, principalmente com a descoberta de ouro nas Minas Gerais. Posterior a Salvador, gradativamente, Rio de Janeiro, torna-se a principal capital do país do século XVIII até o ano de 1960. Durante 197 anos, quase dois séculos, o Rio de Janeiro foi o centro da economia e da política nacional.

A população negra das urbes de Salvador e Rio de Janeiro, foi responsável por quase tudo o que foi edificado, desde as habitações, igrejas, pontes, ruas, praças e 
avenidas, enfim, o ambiente construído foi edificado pela população africana e afrobrasileira.

Além da produção social do espaço, negros e negras inscreveram no chão das cidades a cultura e as identidades brasileiras. Nas considerações de Renato Ortiz (2000) e Marilena de Souza Chauí (2000), a fundação do país se fez por intermédio das culturas indígenas, africanas e afro-brasileiras e portuguesa. A fundação do país se fez com o derramamento de sangue e o trabalho escravizado.

Após 388 anos da sociedade escravocrata, a relação entre negros e brancos não foi nada democrática, por exemplo, as oportunidades no mercado de trabalho, o rendimento, o acesso ao lugar de morar, em geral, são desiguais. Gradativamente, a distância das desigualdades entre negros e brancos foi crescendo, conforme o desenvolvimento das cidades, das oportunidades e da inscrição do racismo na sociedade.

Os dados abaixo do Censo Demográfico do IBGE 2000, o país apresentava 169.872.856 pessoas em todo o território nacional. Deste universo, a população negra representava $44,57 \%$ e a população branca alcançava $53,74 \%$. Dez anos depois, o país alcançou a soma de 190.767 .799 pessoas, deste quadro, $50,90 \%$ da população era constituída por negros e 47,50\% constituída por brancos.

O crescimento da população negra neste século XXI, além de ser um aspecto do crescimento demográfico, a relevância está pautada nas lutas dos movimentos sociais negros diante do racismo e das desigualdades. Nos últimos 132 anos, os movimentos sociais negros veem empreendendo protagonismo para o fortalecimento das identidades e das territorialidades, por intermédio da educação, das mulheres negras, do combate ao racismo e da proposição de políticas de promoção da igualdade étnico racial (TEODORO, 2008; OLIVEIRA, 2016).

No século XX, apenas na passagem de 1950 para 1960 que a capital paulistana alcançou o posto e sede da economia nacional e global em solo brasileiro. Até o final de 1980, São Paulo e a região metropolitana representavam a territorialidade da industrialização, posteriormente, com as políticas neoliberais e a globalização do capital, lentamente, a força de trabalho foi perdendo a sua força, desde as formas de sindicalização e as novas faces do desemprego estrutural em massa. 
Oliveira (2016) observou a urbe paulistana durante o século XX e as primeiras décadas do século XXI, obteve as seguintes interpretações; de um lado a questão do território e das territorialidades negras e, de outro lado, a segregação da população negra.

O território negro se desenvolveu mediante o quadro social do cotidiano e do racismo, por exemplo, a produção das identidades negras, a luta no combate ao racismo e a necropolítica.

A segregação racial reservou aos negros, lugares e posições sociais de subrepresentação socioeconômica, política e cultural, quando comparadas à população branca. Brancos e negros, vivem e trabalham na cidade e nos territórios, no entanto, a população branca de todos os estratos sociais, como as classes média e alta, obtiveram vantagens e benefícios com o racismo estrutural que afeta todos os negros. A população negra, com as desigualdades e o racismo está sobrerrepresentada nos menores rendimentos, mesmo alcançando o mesmo tempo de escolaridade do branco.

Tabela 1. Distribuição da População Negra e Brancas nas principais cidades do país.

\begin{tabular}{|l|r|r|r|r|r|r|}
\hline \multicolumn{5}{|c|}{2000} & \multicolumn{3}{c|}{2010} \\
\hline $\begin{array}{l}\text { Brasil } \\
\text { Município }\end{array}$ & Total & Branca & Negra & Total & Branca & Negra \\
\hline Brasil & 169872856 & 91298042 & 75724428 & 190755799 & 90621281 & 97176614 \\
\hline São Paulo & 10455546 & 6988908 & 3133315 & 11253503 & 683004 & 4164505 \\
\hline Rio de Janeiro & 5875904 & 3429103 & 2356478 & 6320446 & 3239888 & 3026823 \\
\hline Salvador & 2443107 & 562834 & 1837469 & 2675656 & 505739 & 2120095 \\
\hline Fortaleza & 2141402 & 884113 & 1238804 & 2452185 & 888933 & 1527181 \\
\hline Brasília & 2051146 & 108199 & 1016767 & 2570160 & 1075079 & 1444478 \\
\hline Manaus & 1405835 & 448156 & 932959 & 1802014 & 475997 & 1300376 \\
\hline Belo Horizonte & 2238526 & 1190070 & 1013724 & 2375151 & 1101397 & 1244006 \\
\hline Belém & 1280614 & 404779 & 859762 & 1393399 & 372490 & 1006462 \\
\hline Recife & 1422905 & 651161 & 757287 & 1537704 & 628735 & 890464 \\
\hline São Luís & 870028 & 272639 & 587301 & 1014837 & 295487 & 706508 \\
\hline Goiânia & 1093007 & 625922 & 452865 & 1302001 & 621562 & 656484 \\
\hline
\end{tabular}

Fonte: Banco Sidra, IBGE, 2010. Elaboração do autor.

Destaco, na observação do século XX sobre o negro na capital paulistana, o seguinte quadro: nos territórios e territorialidades negras, os lugares do não-racismo foram centrais para o desenvolvimento das práticas de organização social, cultural e política, fortalecendo ao mesmo tempo o espaço social, os pedaços e os lugares de vida e trabalho da população negra; a segregação racial repercutiu em todos os lugares e 
espaços sociais, de forma institucional e estrutural, pode ser desenhada como os lugares de maior status, poder econômico e político, ou seja, os negros são maioria na pobreza e são inexpressivos na condição das classes média e alta.

Neste século XXI, um desafio importante será fazer do território negro uma força capaz de eliminar a segregação racial. Mas para isso, a sociedade não poderá cometer os mesmos erros do século XX, com a aplicação das políticas antinegritude.

Os espaços étnicos raciais não devem ser exclusivos a um grupo sociocultural, a diversidade cultural deveria estar acessível em todas as urbes, em suas diferentes expressões de classe social, gênero, etnia raça, enfim, ela será democrática se a igualdade e a diferença corresponder à todos, sobretudo ao grupo deixado à margem da marginalidade e da vulnerabilidade (GONÇALVES e SILVA, 1998)

Neste século XXI, o grande desafio das urbes do país será exatamente este, tornar os territórios e as territorialidades o lugar das diferenças e da igualdade. Durante os últimos 132 anos, as ciências da cidade aplicaram a política antinegro no Brasil. A produção de ideias sobre territórios e segregação racial tem proporcionado lugares de reflexão e ação política em torno da diversidade e da igualdade, é um processo lento, porém, necessário para transformar a história das cidades em torno da construção de cidades democráticas e cidadãs.

Seguindo a ordem da tabela 1 acima, destaco a participação, de forma crescente da população negra nas seguintes urbes: em primeiro lugar, a capital de São Paulo, seguida de Rio de Janeiro, Salvador, Fortaleza, a capital federal Brasília, Manaus, Belo Horizonte, Belém, Recife, São Luiz e Goiânia.

A cidade do Rio de Janeiro, recebeu algumas abordagens, dentre elas, Andrelino Campos (2007; 2013), observou a transmutação dos quilombos às favelas contemporâneas. Para o autor, o espaço geográfico é um tema da interdisciplinaridade para melhor compreender a formação e desenvolvimento do direito à cidade, sobretudo da luta contra o racismo e as desigualdades.

Compreender a formação do sujeito não é uma das tarefas fáceis na história socioespacial brasileira. As políticas de desqualificação dos movimentos populares, sobretudo de negros e negras, de luta pela terra e contra a propriedade de grandes latifúndios, sempre foram práticas combatidas pelos grupos hegemônicos, onde estes personagens aparecem quase sempre como coadjuvantes. Os espaços de resistência constituídos por negros(as) e pardos no 
urbano ou no campo, por meio do Campesinato, foram alvo de ataques sistemáticos ao longo dos últimos séculos, por exemplo, a transmutação de quilombo em favela, que não fez reduzir os estigmas que pairam sobre os negros e negras no Brasil. $\mathrm{O}$ acesso desigual ao mundo do trabalho, à propriedade da terra, à educação e à saúde, além de muita dificuldade de se localizar nas cidades e/ou no campo, são alguns desses estigmas (CAMPOS, 2013, 227).

A capital mais negra do país, em dados relativos, Salvador, alcançou 79\% de participação de homens e mulheres negras, no censo de 2010. Salvador é a capital de maior sobrerrepresentação dentre as principais do ponto de vista demográfico, no entanto, o racismo, as desigualdades e a branquitude, reservam para a população branca os melhores lugares e posições na terceira maior urbe do país.

A pesquisadora Antonia dos Santos Garcia (2013), historicamente, vem se dedicando em observar como a segregação e as desigualdades tem ocupado o chão da cidade de Salvador.

Para compreender a peculiaridade dos problemas urbanos e seu rebatimento nos processos de segregação seria necessário entende-los no conjunto de posições dos sujeitos e suas várias formas de subordinação cultural, racial e sexual. Nas sociedades contemporâneas, com o grau de urbanização existente, faz-se necessário compreender teórica e empiricamente todas as implicações das formas de organização das cidades, do urbano (GARCIA, 2013).

Parece que não há diferenças socioeconômicas nas urbes com participação negra abaixo e acima da média nacional. A massa negra aparenta estar confinada à segregação e ao racismo, estrutural e institucional.

São Paulo, conforme o último censo, os negros representam $37 \%$ da população do território. Em dados absolutos, eles são mais de 4 milhões dentre as urbes do país. Oliveira (2008; 20016) analisou que da pós-abolição até 2010, a segregação racial prevaleceu na cidade de São Paulo, refletindo a sobrerepresentação no desemprego, nos menores rendimentos e no quadro da necropolítica.

De 2000 a 2010, Oliveira refere-se ao avanço da segregação racial com as classes média e alta se distanciando dos pobres e negros. Elas foram cada vez mais em direção dos enclaves fortificados que são os condomínios fechados, verticais e horizontais, protegidos por segurança física e virtual (CALDEIRA, 2000). Da parte dos negros, em razão das desigualdades e do racismo, eles foram migrando em direção aos 
limites das periferias e também nas periferias dos municípios vizinhos, como Mauá, Franco da Rocha, Guarulhos, nos municípios que formam a Região Metropolitana de São Paulo.

$\mathrm{Na}$ capital de Minas Gerais, Belo Horizonte, negros e negras representam $52,37 \%$ da população. Nesta urbe, a segregação urbana e racial, observada por Lisandra Mara Silva (2018), os lugares dos ricos são habitados por brancos e os lugares dos pobres são habitados por pretos e pardos. Além das favelas, a população negra é maioria nos conjuntos habitacionais de interesse social e residencial.

Oliveira (2008; 2013; 2018), Garcia (2010; 2013) e Silva (2018) compartilham das mesmas analises sobre a segregação urbana e racial nas urbes de Salvador, São Paulo, Rio de Janeiro e Belo Horizonte: para os autores, quanto mais periférica a região, maior o número de pessoas negras moradoras dessas áreas; é maior o número de negros em habitações subnormais; é maior o número da massa negra no mercado informal e no quadro do desemprego, dentre outros quadros das desigualdades urbanas e raciais.

Nas urbes do Sul do país, por exemplo, em Porto Alegre, a pesquisadora Daniele Vieira (2017), observou os territórios negros, de 1800 a 1970. Segundo a autora, no período colonial, os territórios negros estavam concentrados no núcleo central ou nas adjacências. Posteriormente, no pós-abolição, os núcleos negros seguiram em direção aos eixos de expansão do espaço central: os eixos sul e leste.

Em Porto Alegre, Vieira destaca que no pós-abolição os seguintes espaços negros: o Areal da Baronesa, a Rua 13 de maio e a Ilhota, como lugares de trabalho, habitação e cultura dos territórios negros. Estes pedaços e lugares foram palco das territorialidades negras até o final de 1960 e 1970. Na capital do Rio Grande do Sul, os negros alcançam $20,2 \%$ da população, quanto aos brancos, eles são 79,2\% do universo local.

Hoje, o capitalismo nacional e internacional em solo sul-rio-grandense, modificou o quadro das territorialidades negras. Com o desenvolvimento da cidade, gradativamente, a população dos territórios negros foi sendo expulsa, em direção às áreas da pobreza cada vez mais distante das áreas ricas e desenvolvidas.

Na capital de Santa Catarina, a ilha de Florianópolis também reserva em seu território as territorialidades negras. Azânia Mahin Nogueira (2018), observa que os territórios negros sempre estiveram inscritos no chão da cidade. Para a autora, criou-se 
um mito da inexistência da população negra em Florianópolis, reforçado pela ideia de que no sul do país não houve uso de mão de obra escrava de origem africana ou afrobrasileira.

A invisibilização da população negra, na história e no momento atual, alimenta o discurso racista de que o desenvolvimento socioeconômico, política e cultural deve ser creditado apenas aos imigrantes europeus e seus descendentes.

Nogueira (2018) destaca que na ilha de Santa Catarina, oficialmente, os negros estavam ali desde 1880. Gradativamente, na história da cidade, os territórios negros foram se estruturando nas áreas centrais: o Mercado Municipal, no decorrer do século $\mathrm{XX}$, os locais de origem foram sofrendo a desterritorialização e reterritorialização, em direção aos distritos de sobrerrepresentação negra, como Barra da Lagoa, São João do Rio Vermelho e, em especial, Cachoeira do Bom Jesus.

Florianópolis, capital de Santa Catarina, segundo os dados do Censo Demográfico do IBGE 2010, os negros correspondiam a 61.266 dos habitantes, $14,54 \%$ da população local.

Nas cidades brasileiras, a existência de territórios e territorialidades negras comprovam que a população vem produzindo espaços que lhes protejam do racismo, das desigualdades e da necropolítica.

Outra característica urbana e étnico racial do Sul do país, situa-se na cidade de Londrina, negros e negras representam $26 \%$ da população local. Em Londrina, Maria Nilza da Silva e Mariana Panta (2014) destacam as consequências do silenciamento sobre a trajetória dos negros que se manifestam nas desigualdades raciais e em todos os indicadores sociais.

$\mathrm{Na}$ pequena "Londres", o mapa da cidade revela a concentração negra nas regiões de maior pobreza e vulnerabilidade, particularmente nas periferias das zonas sul e norte.

Retomando as informações socioeconômicas de 2010, o rendimento médio no cenário nacional alcançava o valor de $\mathrm{R} \$ 1.344,70$, da população branca $\mathrm{R} \$ 1.705,84 \mathrm{e}$ os ganhos da população negra, $\mathrm{R} \$ 939,06$. No quadro nacional, os trabalhadores negros recebiam aproximadamente $55 \%$ dos ganhos da população branca.

Esta situação não é recente, nos censos de 1991, 2000 e 2010, a diferença de rendimentos entre brancos e negros permaneceu no mesmo patamar entre $40 \%$ a $60 \%$. 
No século $\mathrm{XX}$, principalmente nas três últimas décadas, a população negra recebeu rendimentos abaixo da população branca (OLIVEIRA, 2016).

Na capital federal, concentra-se os maiores rendimentos da população branca e negra: no território local, o rendimento médio alcança $\mathrm{R} \$ 2.584,90$, os brancos recebem $\mathrm{R} \$ 3.589,00$ e os negros $\mathrm{R} \$ 1.757,57$. Na capital do país, a população negra recebe $49 \%$ dos rendimentos da população branca.

Conforme a tabela abaixo, nas dez maiores cidades o rendimento nominal médio da população negra alcança, aproximadamente, de 38\% a 60,35\% dos rendimentos da população branca. A segregação racial proporciona aos negros os menores rendimentos no mercado de trabalho e as menores oportunidades na vida social. A hierarquia socioeconômica e étnico racial aprofunda-se quando incluímos a variável gênero; as mulheres negras recebem os menores rendimentos que os homens brancos e negros e as mulheres brancas.

Tabela 2. Valor do rendimento nominal médio mensal de todos os trabalhos das pessoas de 10 anos ou mais de idade, ocupadas na semana de referência, com rendimento de trabalho (Reais) das dez maiores cidades e capital federal.

\begin{tabular}{|c|c|c|c|c|}
\hline \multirow{2}{*}{ Brasil e Município } & \multicolumn{4}{|c|}{ Cor ou raça -2010} \\
\cline { 2 - 5 } & Total & Branca & Negra & $\begin{array}{c}\text { Diferença de } \\
\text { Negros e } \\
\text { Brancos }\end{array}$ \\
\hline Brasil & 1344,70 & 1705,84 & 939,06 & $55,00 \%$ \\
\hline São Paulo (SP) & 2195,28 & 2752,51 & 1185,53 & $43,07 \%$ \\
\hline Rio de Janeiro (RJ) & 2090,44 & 2802,66 & 1272,73 & $45,41 \%$ \\
\hline Salvador (BA) & 1496,24 & 2870,21 & 1107,35 & $38,50 \%$ \\
\hline Fortaleza (CE) & 1352,78 & 1880,82 & 972,17 & $51,68 \%$ \\
\hline Brasília (DF) & 2584,89 & 3589,62 & 1759,57 & $49,01 \%$ \\
\hline Manaus (AM) & 1462,34 & 2122,00 & 1280,81 & $60,35 \%$ \\
\hline Belo Horizonte (MG) & 2027,24 & 2817,46 & 1270,81 & $45,07 \%$ \\
\hline Belém (PA) & 1469,63 & 2198,05 & 1165,26 & $53,01 \%$ \\
\hline Recife (PE) & 1755,61 & 2536,65 & 1082,51 & $42,67 \%$ \\
\hline São Luís (MA) & 1411,93 & 2149,03 & 1064,03 & $49,51 \%$ \\
\hline Goiânia (GO) & 1894,66 & 2337,72 & 1392,07 & $59,54 \%$ \\
\hline
\end{tabular}

Fonte dos Dados: Banco Sidra do IBGE, 2010. Elaborado pelo autor.

É importante destacar que cidades com população negra acima da média nacional, como Salvador, Fortaleza, Recife, Manaus, Belém, São Luís e Belo Horizonte, 
os negros permanecem atrás no quadro socioeconômico. Na capital mais negra do país, Salvador, a força de trabalho negra recebe aproximadamente $38 \%$ dos rendimentos da população branca, que representa apenas $21 \%$ do universo local.

São Paulo e Rio de Janeiro, do ponto de vista absoluto, estão em primeiro e segundo lugares em população negra. Nas duas cidades, as representações do capitalismo local, nacional e global estão mais presentes, em razão do dinamismo que elas assumem no cotidiano do país, em destaque sobressaem os cenários da segregação e do racismo definindo a complexa realidade da hierarquia socioeconômica e étnico racial.

Oliveira (2013) observa que na história do século XX e no momento atual, o retrato das cidades de São Paulo e Rio de Janeiro, revela as faces da interseccionalidade entre as desigualdades urbanas e sociais relacionadas à segregação étnico-racial.

As informações sobre rendimento das dez principais urbes do país, reiteram o cenário da segregação racial e das desigualdades urbanas e sociais no Brasil. Diante da intersecção das desigualdades socioeconômica, espaciais, territoriais e étnico raciais, é urgente a formação de profissionais e especialistas das áreas que retratam a cidade e o urbano.

É urgente a formação de pesquisadores, especialistas, profissionais técnicos e professores no desenvolvimento sobre a cidade e o urbano em intersecção às relações étnico raciais, porque no passado e nos dias de hoje, a segregação racial não proporcionou a cidade da diversidade socioeconômica, cultural, política e étnico racial.

\section{CONSIDERAÇÕES FINAIS}

É recente a interpretação da segregação racial nas cidades brasileiras, por exemplo, a capital federal, as capitais dos estados, as regiões metropolitanas e as urbes pequenas e médias, em geral, predomina a segregação da população negra em intersecção às desigualdades urbanas e sociais, como elementos da necropolítica (OLIVEIRA, 2016).

Após 132 anos da pós-abolição, reitero as reflexões acima, no chão das cidades brasileiras a segregação, urbana e rural, com recorte étnico racial tem assumido a sobrerrepresentação no universo das 5.565 cidades no país. 
Nas 5.565 cidades, o rendimento da população negra é superior em apenas 149 urbes em relação aos ganhos da população branca (não é uma diferença grande, elas são próximas, uma diferença de dez a duzentos reais). Em 97,2\% das cidades brasileiras, temos a sub-representação do rendimento da população negra, esta é uma observação do cenário da segregação racial.

No atual momento, as capitais do país e as principais do capitalismo global, nacional, regional e local, a segregação racial é uma barreira de grande complexidade para o desenvolvimento do país e a edificação da cidadania para todos.

Parte desta construção, deve levar em conta a produção de ideias e lugares que realmente sejam incluídas na agenda de políticas públicas e na formação de capital técnico científico e informacional. É urgente o combate à necropolítica nas cidades brasileiras, conforme as inscrições da segregação e das desigualdades no corpo do texto.

\section{REFERÊNCIAS BIBLIOGRÁFICAS}

BRANDÃO, André Augusto. Miséria da periferia: desigualdades raciais e pobreza na metrópole do Rio de Janeiro. Rio de Janeiro, Pallas Editora, 2004.

CAMPOS, Andrelino. Do quilombo à favela - A produção do espaço criminalizado no Rio de Janeiro. Rio de Janeiro, Bertrand Brasil, 2007.

CARRIL, Lourdes. Quilombo, Favela e Periferia - A longa busca da cidadania. São Paulo, Annablume, Fapesp, 2006.

CASTELLS, Manuel. A Questão Urbana. São Paulo. Editora Paz e Terra, 1983.

COSTA, Emília Viotti. Da Monarquia à República, São Paulo, Editora Brasiliense, 1995.

CHALHOUB, Sidney. Visões da Liberdade: Uma história das últimas décadas da escravidão na corte. São Paulo, Companhia das Letras, 1999.

CHAUI, Marilena de Souza. Brasil: Mito Fundador e Sociedade Autoritária, São Paulo, Editora Perseu Abramo, 2000.

CALDEIRA, Teresa Pires do Rio. Cidade de muros: crime, segregação e cidadania em São Paulo. São Paulo, Editora 34 e EDUSP, 2000.

CORREA, Roberto Lobato. O espaço urbano. São Paulo, Ática, 1995.

FERNANDES, Florestan. A Integração do Negro na Sociedade de Classes. São Paulo, Editora Dominus, 1965.

FERNANDES, Florestan. Significado do Protesto Negro. São Paulo, Editora Cortez, 1989. 
GARCIA, Antonia dos Santos. Desigualdades Raciais e Segregação Urbana em Antigas Capitais, Salvdor, Cidade D'Oxum e Rio de Janeiro, Cidade de Ogum. Rio de Janeiro, Garamond, FAPERJ, 2010.

Relações de Gênero, raça e classe na cidade d'Oxum: educação e segregação espacial. In: A Cidade e o Negro no Brasil: Cidadania e Território. São Paulo, Editora Alameda, 2013.

GONÇALVES, Luiz Alberto Oliveira e SILVA, Petronilha B. Gonçalves. O Jogo das Diferenças - O Multiculturalismo e seus contextos. Belo Horizonte, 1998.

GONZALES, Lélia; HASENBALG, Carlos. O Lugar de Negro. Rio de Janeiro, Marco Zero, 1982.

GUIMARÃES, Antonio Sérgio Alfredo. Racismo e Anti-racismo no Brasil. São Paulo, Editora 34, 1999.

LÉVI-STRAUSS, Claude. Tristes Trópicos. São Paulo, Companhia das Letras, 1996.

MARQUES, Eduardo e TORRES, Haroldo. São Paulo - Segregação, Pobreza e Desigualdades Sociais. São Paulo, SENAC, 2005.

MBEMBE, Achille. Necropolítica. Rio de Janeiro, Revista Arte e Ensaio, n.32, 2016.

NASCIMENTO, Abdias do e SEMOG, Elé. O Griot e as muralhas. Rio de Janeiro, Pallas, 2006.

NASCIMENTO, Abdias do. O Genocídio do Negro Brasileiro - Processo de um racismo mascarado. Rio de Janeiro, Paz e Terra, 1978.

OLIVEIRA, Reinaldo José de. Territorialidade Negra e segregação racial na cidade de São Paulo. São Paulo, Editora Alameda, 2016.

Alameda, 2013.

A Cidade e o Negro no Brasil: Cidadania e Território. São Paulo, Editora

Segregação Urbana e Racial na cidade de São Paulo: as periferias de Brasilândia, Cidade Tiradentes e Jardim Ângela. Tese de Doutorado em Ciências Sociais, PUC SP, 2008. A Presença do Negro na Cidade: Memória e Território da Casa Verde em São Paulo. Mestrado em Ciências Sociais, PUC SP, 2002. A Produção Social do Espaço em Territórios Negros de São Paulo: o Bairro da Barra Funda. Trabalho de Conclusão de Curso em Ciências Sociais, PUC SP, 1998.

ORTIZ, Renato. Cultura Brasileira e Identidade Nacional. São Paulo, Brasiliense, 2000.

PACHECO, Regina Silvia e LEME, Maria Cristina Silva. "A Questão Fundiária, imobiliária e os serviços urbanos: conceitos e referências teóricas em teses e dissertações recentes." Espaço e Debates - Revista de Estudos Urbanos e Regionais, São Paulo, número 28, 1989.

PINTO, Luiz Antonio da Costa. O Negro no Rio de Janeiro - Relações de Raça numa sociedade em mudança. Rio de Janeiro, Editora UFRJ, 1998.

QUIJANO, Anibal. Colonialidade do Poder - Eurocentrimo e América Latina. Buenos Aires, CLACSO, 2005. 
RIBEIRO, Luis César de Queiroz. Dos cortiços aos condomínios fechados: as formas de produção da moradia na cidade do Rio de Janeiro. Rio de Janeiro, Civilização Brasileira, 1997.

ROLNIK, Raquel. A Cidade e a Lei - Legislação, política urbana e território na cidade de São Paulo. São Paulo, Editora Nobel, 1997.

ROMÃO, Azânia Mahin. Territórios Negros em Florianópolis. Florianópolis, Dissertação de Mestrado em Geografia, POSGEO, UFSC, 2018.

SANTOS, Milton. O Espaço do Cidadão. São Paulo, Editora Nobel, 1993.

SILVA, Lisandra Mara. Propriedade, Negritude e Moradia na Produção da Segregação racial da cidade de Belo Horizonte. Escola de Arquitetura da UFMG, 2018.

SILVA, Maria Nilza da e PANTA, Mariana. Território e Segregação Urbana - O Lugar da população Negra na cidade de Londrina. Londrina, Universidade Estadual de Londrina, 2014.

SILVA, Maria Nilza da. Nem para todos é a cidade: segregação urbana e racial em São Paulo. Brasília: Fundação Cultural Palmares, 2006.

SOUZA, Regina Marques de e OLIVEIRA, Reinaldo José de. Corpos em Cena nas Metrópoles Globais: meninas negras, processos de subjetivação e cinema. Revista da ABPN, v.7, n.15, p.175-191, 2015.

VARGAS, João H. Costa. "Desidentificação": A lógica de exclusão antinegra no Brasil. In: PINHO, Osmundo e VARGAS, João. ANTINEGRITUDE - O Impossível sujeito negro na formação social Brasileira. Belo Horizonte, Cruz das almas, UFRB, 2016.

VARGAS, João H. Costa. Apartheid Brasileiro: Raça e Segregação no Rio de Janeiro. Revista de Antropologia, USP, 2005.

VÉRAS, Maura Pardini Bicudo Véras. Trocando Olhares - Uma Introdução à Construção Sociológica da Cidade. São Paulo, EDUC, Studio Nobel, 2000.

VIEIRA, Daniele Machado. Territórios Negros em Porto Alegre (1800-1970): Geografia histórica e presença negra no espaço urbano. Porto Alegre, Dissertação de Mestrado em Geografia, Instituto de Geociências, UFRS, 2017.

VILLAÇA, Flavio. Espaço Intra-Urbano no Brasil. São Paulo, Studio Nobel, 2001.

Recebido em: $22 / 09 / 2020$

Aceito em: 30/10/2020 